"five" for a "three" unless we have all our wits about us. Should such a slip occur we prefer to look upon it as a slip and not ascribe it to ignorance.

In dealing with patients, it is a truism to say, as we have observed on previous occasions, that they sometimes invert the sequence and blame us for things we could'nt help and, more rarely perhaps, praise us for some result when we know in our heart of hearts that we have deserved blame rather than praise. Say what you like, no one objects to praise in moderation. Blame is not so easy for us to be satisfied with; but there is one occasion in which the person blamed may derive an-unholy gusto, and that is when he can prove the blamer to be wrong. A very early experience of the writer's was of this nature. We had just come into residence as house surgeon and had to assist one of the assistant surgeons who was not normally attached to our firm. The operation was that of complete removal of the breast. We were subjected to a running fire of caustic criticism until, about a third of the way through, we were asked why in heaven's name we did not put a clip on that vessel. The vessel in question was the intercosto-humeral nerve and we protested that an artery forceps there was out of place. The rest of the operation was completed in silence, and we thanked God that he had allowed us to remember this elementary anatomical point.

\title{
THE OPHTHALMOLOGICAL SOCIETY OF AUSTRALIA (British Medical Association)
}

\section{Annual Meeting}

THE seventh annual general and scientific meeting of the Ophthalmological Society of Australia (British Medical Association) was held at the Royal Australasian College of Physicians, Macquarie Street, Sydney, on September 23, 1947: Dr. Darcy A. Williams, the President, in the chair. Those present included three members from Queensland, thirty-seven from New South Wales, thirteen from Victoria, two from Tasmania, four from South Australia and one from Western Australia.

\section{President's address}

The President, Dr. Darcy A. Williams, after welcoming such guests as had been able to attend, addressed members upon the subject of early ophthalmologists in Australasia and upon the associations of ophthalmologists with Australasian medical congresses. Amongst the early ophthalmologists mentioned by the 
President were James T. Rudall, Andrew S. Gray, T. Aubrey Bowen, Charles Gosse, Thomas Evans and W. Odillo Maher.

The gradual growth of ophthalmology was traced and the manner in which it kept pace with changes overseas was described. An endeavour was made to salvage from the past valuable material and interesting and at times amusing anecdotes.

\section{Research technique and training overseas}

N. M. Macindoe (Sydney) who had recently returned from a visit to Europe and the U.S.A. where he had made close enquiries into subjects of ophthalmological interest, read two papers, accompanied by fifty illustrations, showing recent advances in research and technique, and trends in organisation and training abroad. At Boston research was concerned with the subject of steamy cornea, optic neuritis and the visual acuity of moving, objects; at Johns Hopkins with virus diseases and sympathetic ophthalmia; at $\mathrm{New}$ York with colour vision; at Lundon with paretic strabismus; at Copenhagen with colloidometry; and at Stockholm with chromatic light and electro-retinograms. At Zurich work was being done on corneal distortion, subjective screens for central scotomata, perimetry, slit-lamp examination of the fundus, the content of the pathological aqueous, tonometry and ciliary permeability. New technique described included gonioscopy, drug treatments, radio-active iodine, scleral resection in myopia, corneal grafting, glaucoma, cataract and retinal detachment operations.

The section on training was a reasoned appeal for more apprenticeship and fewer academic examinations. The continental clinic system was described and the suggestion put forward that we copy the American type of organisation in our big centres.

\section{An outline of orthoptics in New South Wales}

Miss E. Russell read a composite paper expressing the general opinion and experience of five senior practising orthoptists. The practice of orthoptics by orthoptists began in Sydney in 1933. At the present time eleven orthoptists were working in hospitals, intermediate clinics and private practice, and an average of 576 treatments were given each week.

In the early years, squint formed the great majority of cases, prisms being used for phorias as a general means of relieving or attempting to relieve symptoms. While the treatment of strabismus went on in growing numbers, the realisation of the great benefit orthoptic treatment was to phorias and their allied types had widened this field amazingly. Phorias of all types were receiving increasing attention since these were the cases where distress might 
be acute. Orthoptists felt that their greatest battle was still with strabismus and it was there that they did their toughest job. They had learnt during the years to assess the relative possibilities of success with the different types. With all types suppression was their greatest enemy.

As regards convergent squints, true accommodative cases responded to treatment only and borderline squints needed surgical help. Tonic squints required orthoptics before and after surgery. Congenital cases were often successfully treated.

The treatment of divergent squint was less difficult. With all cases of strabismus orthoptic investigation was important before surgery to assess the binocular condition, i.e., abnormal projection, etc. Suppression was their greatest enemy. Occlusion was their greatest ally. Treatment had been speeded up generally. There would always be cases, difficult in themselves, and rendered more so by mental dullness, inability to concentrate, frail health and indifferent parental co-operation, where treatment would be lengthy which eventually could be cured or greatly improved. As long as definite progress was being made they felt treatment should continue.

\section{The selection of patients for orthoptics : some remarks :- John Antill Pockley. Sydney}

Some factors in the selection of cases for orthoptics were indicated. It was concluded that the personality of the patient and parent was of first importance in the selection of many cases and that in adults many phorias arose from psychogenic causes. It was desirable to aim at the earliest possible cure and when conditions were suitable operation should be early. Waiting for your children to reach orthoptic age was undesirable. A close liason between ophthalmic surgeon and orthoptist was essential.

\section{Two cases of choroidal melanomata with unusual histories}

Dr. Kevin O'Day (Melbourne) read a paper on two cases of intraocular tumours of unusual interest.

The first was a malignant melanoma of the choroid. Four years before the eye was finally removed, the patient had been advised by four ophthalmic surgeons that removal was necessary because of a malignant tumour. Even after four years the tumour was not very large. The eye was slightly inflamed, but there was no evidence of glaucoma. Very little pigment was present in the tumour. There was a metastatic nodule at the root of the iris. The tumour was of mixed-celled type with many thin-walled blood sinuses. Mitotic figures were very difficult to demonstrate. Wilder's stain demonstrated dense reticulin in the base of the tumour, with very little at 
the summit where it had broken through Bruch's membrane. Wilder was of the opinion that the prognosis was better in tumours with a dense reticulin. The speaker suggested that this stain should be done on every case in which the eye was excised because of its probable prognostic significance.

The second case was a retino-blastoma in a man aged 29 years, an unusual age for this tumour. The patient gave a history of loss of vision, and pain in the eye after an injury at football, When first seen the vision was reduced to hand movements in the temporal field. The tension was raised and the anterior chamber full of blood. After cyclodialysis the pain and the tension were relieved and the man went back to the country. He returned a year later with the history of a further blow at football, and the eye completely blind and painful. The tension was raised and the eye-ball enlarged with a ciliary staphyloma on the temporal side. The anterior chamber was full of blood. The eye was excised. When it was opened, the tumour was found to involve the retina, the iris, ciliary body and the anterior chamber. A cyclitic membrane was present, and the tumour cells were growing along this. A portion in the ciliary body was anaplastic, but sections of the retina demonstrated the mantles of cells surrounding vessels, typical of retino-blastoma. Actively growing areas alternated with necrotic ones. There was no evidence of extra-ocular extension, although mitotic figures were very numerous.

\section{The treatment of dendritic ulcer}

Dr. Frank Phillips (Hobart) described his treatment for dendritic ulcer, which included removal of the damaged tissue with blotting paper and the use of a dental drill on the more resistant areas of ulceration. He maintained that his treatment was better than the customary methods.

\section{Endothelial dystrophy}

Dr. Clifford S. Colvin (New South Wales) described a case of endothelial dystrophy in a female patient aged 62 years. The case showed improvement after glandular and vitamin therapy. Dr. Colvin concluded his paper with an illuminating discussion on this uncommon and interesting condition.

\section{Dry Eyes-a further contribution to their study}

Dr. J. Bruce Hamilton (Hobart) gave a paper on the subject of kerato-conjunctivitis sicca, amplifying his paper read before the Society in 1940 (Transactions, Vol. XI). He reported another 24 cases and described their treatment, which had generally satisfactory 
results. Dr. Hamilton discussed the differential diagnosis of the condition and its relation to Mikulicz's disease, Plummer-Vinson syndrome and iodide mumps.

$\mathrm{He}$ pointed out that the disease was of great interest in its possible association with other common morbid processes.

\section{Allergic sensitivity to procaine hydrochloride and the hypodermic injection of cocaine hydrochloride-a personal experience}

Dr. Arthur D'Ombrain (Sydney) dealt with the characteristics of drug allergy and he gave a harrowing personal experience of dermatitis due to procaine. He maintained that collapse from cocaine injection was really an outright poisoning and not an anaphylactic reaction. He related personal experience in the use by injection of 0.75 per cent. cocaine hydrochloride, over a period of six years. Dr. D'Ombrain's opinion was that cocaine could be injected with safety, provided a correct concentration and dosage were used.

\section{Eye protection in industry}

Dr. A. L. Tostevin (Adelaide) stressed the necessity for greater co-operation between oculists, industrialists, lighting engineers, architects, the Nation Safety Council and the Standards Association in regard to, not only the protection of eyes in industry, but also in the field of sight testing and correction of vision of employees.

Examples of eye injuries in the various large industries were given and reference was made to the I.C.A. Safety Council as a guide to industry towards protecting the worker and improving his efficiency. Emphasis was placed on the fact that most of the metal industries showed that 50 per cent. of the lost time from accidents was due to eye injuries.

Dr. Tostevin surveyed the research work being carried out in Australia and also the measures to be taken in prevention of eye injuries generally.

\section{A Case of partial thrombosis of the central retinal vein treated by dicoumarin}

Dr. R. G. Banks-Smith (New South Wales) gave extracts from available literature on this subject. The types of this condition were described and indication was given of those types in which treatment might be successful.

Dr. Banks-Smith submitted a case report in which partial suc'cess was claimed and he issued a warning as to the possibilities of overdosage. 


\section{Radon treatment of intra-ocular tumour.}

Dr. W. Lockhart Gibson (I3risbane) sketched a short history of the various methods of radiation that had been used, and drew attention to, the value of active co-operation of the biophysicists with the radiotherapists in working out accurate dosage. $\mathrm{He}$ described the use of a radon seed bent into the form of a circle with a spoke in it and moulded to the curve of the globe of the eye. Dr. Gibson claimed that such a seed was easy to suture in position, and could be arranged to give an accurate dosage to the tumour and as little radiation as possible to those parts of the eye which were so extremely sensitive to radiation.

Charts of isodosage were exhibited and the treatment of a child with two tumours in its only eye was described.

\section{The Lagrange operation-a summary of sixty cases}

Dr. J. A. O'Brien (Melbourne) presented a summary of sixty cases of Lagrange operation for glaucoma. He explained various modifications of technique. His results with complete or buttonhole iridectomy were similar and his percentage of successful operations totalled eighty-five.

\section{A preliminary survey of ophthalmic diseases in Western New South Wales}

Dr. K. B. Redmond (New South Wales) analysed two thousand case records of patients in Western New South Wales, taking into account the geographical area of residence and evironmental conditions of life and work. The areas included part of centre tablelands, the central western slope and the western plains. He concluded that factors of sunshine, dryness, glare and dust were important. He presented a table of ophthalmic diseases and their percentage incidence.

\section{Non-magnetic metallic intra-ocular foreign body}

Dr. Lennox Price (Newcastle) said that in civil practice it was unusual to meet a case of penetrating wound of the eye with a retained, intra-ocular foreign body which was metallic and yet nonmagnetic. Under war conditions, on the other hand, such cases occurred more commonly.

Reports were given of two cases of this type which were treated within a few weeks of each other. The histories, clinical features and results in each case were compared and contrasted. 


\section{Optic neuritis following measles}

Dr. T. C. Meurer (New South Wales) dealt with optic neuritis and post-neuritic optic atrophy following measles. He said that the condition was a result of an encephalomyelitis which occurred late in the course of measles usually when the rash was beginning to fade. The resulting optic atrophy did not appear to have any relation to the severity of the encephalomyelitis or the severity of the attack of measles. Three cases were reported and a review of the literature presented.

\section{Social}

The annual dinner was held at the Royal Automobile Club of Australia and was attended by forty-two members and guests.

On the evening of the opening day a cocktail party was given at the Wentworth Hotel by the Ophthalmological Society of New South Wales to members and their ladies.

The President offered the congratulations of the Society to Dr. J. Bruce Hamilton who had been appointed President of the Section of Ophthalmology of the British Medical Association Congress, Sixth Session, Perth.

Dr. Hamilton was also congratulated on his election as President of the British Medical Association, Tasmanian Branch.

\section{Annual General Meeting}

The annual general meeting dealt with general business. Dr. Claude Morlet was elected President for the ensuing year, and Dr. Arthur H. Joyce, Vice-President.

It is proposed to hold the eighth annual general and scientific meeting at Perth in conjunction with the British Medical Association Congress Sixth Session, August 15 to 21, 1948.

\section{CORRESPONDENCE}

\section{COLOUR VISION IN THE CONSULTING ROOM}

To the Editors of THE BRITISH JOURNAL OF OPHTHALMOLOGY.

DEAR SIRS,-It is not important to argue further on the differing incidence of defective colour vision in the normal male population and in the series examined by Dr. Neubert. All I wished to do in this connection was to suggest an alternative explanation to that offered by the original author. This can hardly be classed as illogical. 